\title{
Efficacy of Tourniquet Application in Minimizing Intraoperative Blood Loss in Cesarean Hysterectomies for Placenta Accreta-A Comparative Study
}

\author{
Pushplata Sankhwar*, Shyam Pyari Jaiswar, Sujata Deo, Devyani Misra, Neha Negi \\ Department of Obstetrics and Gynaecology, King George's Medical University, Lucknow, India \\ Email: sankhwar_pushpa@yahoo.com
}

Received 30 September 2014; revised 25 October 2014; accepted 21 November 2014

Academic Editor: Yasam Kemal Akpak, Ankara Mevki Military Hospital, Turkey

Copyright (C) 2014 by authors and Scientific Research Publishing Inc.

This work is licensed under the Creative Commons Attribution International License (CC BY). http://creativecommons.org/licenses/by/4.0/

(c) ()

\begin{abstract}
Objective: To assess the effect of tourniquet application of intraoperative blood loss in placenta accreta cases undergoing cesarean hysterectomy. Materials and methods: Nine cases and twenty controls with USG and colour Doppler diagnosed placenta accreta with previous cesarean section were chosen to utilize this novel approach. These cases were planned for elective cesarean section followed by hysterectomy. The twenty controls underwent a classical cesarean section followed by total abdominal hysterectomy with the placenta in situ. Among the nine cases, after delivery of the fetus through upper segment cesarean section, a cotton gauze tourniquet was applied all around the lower pole of uterus. Hysterectomy was performed with placenta in situ. Abdomen closed after achieving complete haemostasis. Results: The average operative time taken was $85 \pm 11.72$ minutes among cases and $98.25 \pm 9.9$ minutes among controls $(p=0.0039)$. Average blood loss was $1011.11 \pm 99.3 \mathrm{ml}$ among the cases and $1855 \pm 222.95 \mathrm{ml}$ among the controls $(p \leq 0.0001)$. Average requirement of blood transfusion required was two units for the cases and five units for the controls $(p=0.0002)$. No intra-operative or post-operative surgical complications were observed in any of the cases whereas the controls reportedly had a few. All the mothers and babies were healthy at the time of discharge. Conclusion: The presence of placenta accreta is associated with major fetal and maternal complications. The technique of tourniquet application is efficacious in minimizing the intra-operative blood loss and surgical complications due to obstruction of operative field by bleeding and also by preventing massive blood transfusion related complications.
\end{abstract}

\footnotetext{
*Corresponding author.
} 


\section{Keywords}

\section{Placenta Accreta, Post-Partum Haemorrhage, Tourniquet}

\section{Introduction}

Placenta accreta is a potentially life-threatening obstetric condition that requires a multidisciplinary approach of management [1]. The incidence of placenta accreta increases in presence of placenta praevia with prior caesarean sections. [2]. Reported incidence of placenta accreta is nearly $10 \%$ in cases of placenta praevia and rises upto $40 \%$ in women who have an anterior placenta and $\geq 2$ previous caesarean deliveries [3]. In a phenomenal study comprising 39,244 women undergoing caesarean hysterectomy, the incidence of placenta accreta was found to be 38\% [4]. Diagnosis of placenta accreta during antenatal period allows skilful planning in an attempt to minimize potential maternal or neonatal morbidity and mortality. Maternal morbidity is reportedly less in cases with antenatal suspicion of placenta accreta who undergo scheduled delivery when compared with emergent delivery [5].

In general, the recommended management of suspected placenta accreta is a planned preterm classical caesarean followed by hysterectomy with the placenta in situ since attempts at removal of the placenta may result in torrential haemorrhage endangering the patient's life. However, a contingency plan for an emergency delivery should be developed individualizing each case [6]. Various precautions and techniques to reduce blood loss may be incorporated which include hypotensive anaesthesia, hemostatic sutures in placental bed and myometrium, stepwise devascularisation of uterus including uterine artery ligation, ovarian artery ligation, internal iliac artery ligation and embolization. Cesarean hysterectomy is a last resort to control intractable haemorrhage.

The most common cause of maternal mortality in cases of placenta accreta is massive haemorrhage and complications associated with massive blood transfusion. The average blood loss in cases of placenta accreta has been reported between 3000 - $5000 \mathrm{ml}$ [7]. Most of the patients with placenta accreta require blood transfusion and some may even need massive blood transfusions. Reported maternal mortality associated with placenta accreta is as high as $7 \%$ [8].

Tourniquet has well established role in vascular surgeries, myomectomies and other surgeries as well. We used the underexplored novel technique of tourniquet application in placenta accreta cases and got promising results to minimize intra-operative haemorrhage.

\section{Materials and Methods}

This study was conducted in the Department of Obstetrics and Gynaecology, King George’s Medical University over a period of two years from July $1^{\text {st }} 2012$ to June $30^{\text {th }} 2014$. The study was approved by the local Ethical committee KGMU, Lucknow (07/2012). Twenty-nine subjects with prior scarred uterus and ultrasonography (USG) Doppler diagnosed placenta accreta were enrolled after critical evaluation with a detailed history and physical examination. USG findings of placental lacunae, absence of the retroplacental clear zone and interruption of posterior bladder wall-uterine interface on the gray-scale and colour Doppler findings of blood vessels crossing the tissue-interface disruption sites were presumed to be diagnostic of placenta accreta. The subjects were randomly allocated into the intervention and control groups. Out of the total subjects enrolled, every third subject was enrolled into the intervention group to avoid any selection bias. So, the subjects were grouped as 9 cases (intervention group) and 20 controls. The number of controls was twice the number of cases.

Preoperatively, routine investigations including haemoglobin $(\mathrm{Hb})$, haematocrit (hct), urinanalysis, blood group, viral markers, liver function tests, kidney function tests, bleeding time, clotting time and platelets were done. The subjects were planned for cesarean hysterectomy under general anaesthesia after their written informed consent. Adequate blood was arranged pre-operatively. Surgery was performed by a team of trained and competent obstetricians. Abdomen was opened through longitudinal infra-umbilical incision to facilitate proper exposure and the extent of invasion was assessed per-operatively. Utero-vesical fold of peritoneum was opened and bladder pushed down gently as low as possible. Any adhesions between omentum, anterior abdominal wall or peritoneum were dissected (Figure 1). An incision was given in the upper uterine segment in midline or high 
transverse in lower segment if it was free of placental invasion, through which the fetus was delivered. Cord was clamped and baby handed over to the Pediatrician. The placenta was left in situ. In nine of the subjects (intervention group), the uterus was then exteriorized and a window of $2-3 \mathrm{~cm}$ was created on both sides in the broad ligament just lateral to uterine wall near the lower uterine segment. Clamps were applied on the cornual structures on both the sides (Figure 2). Using cotton roller gauze as a tourniquet, it was passed through the broad ligament window and thereafter the knot was tied in the lower pole of uterus as low as possible. Among the various options for tourniquet, we preferred the cotton roller gauze as it is easily available and has a firm grip over the tissues due to its roughness. This step hampered the uterine blood supply tremendously and controlled the bleeding from uterine edges and placental bed. The round ligaments were then clamped cut and ligated bilaterally followed by tubo-ovarian ligaments (Figure 3). Utero-vesical fold was then further dissected using scissors and the bladder was pushed down. In two of the cases a second and in one even a third tourniquet was applied below the first one. This was required in cases where bleeding persisted from the uterine edges despite application of a single tourniquet due to loosening of the knot or, the first tourniquet was ineffective in reducing blood loss because of a broad lower uterine segment due to placenta praevia. The remaining steps of total hysterectomy were performed as usual. The specimen of uterus with placenta in situ was delivered out with tourniquet in place as seen in the photographs (Figure 4 and Figure 5). Abdominal drain was put as per need in three cases. Abdomen was closed after achieving complete haemostasis, instruments and sponges count. The amount of blood loss was calculated by counting and weighing the sponges used, weighing the clots that were removed and the blood collected in the graduated suction jar. All patients stood the procedure well.

Among the other twenty subjects (controls), after pushing down the bladder, the fetus was delivered by an upper segment or a high transverse section. The placenta was left in situ. This was followed by immediate exte-

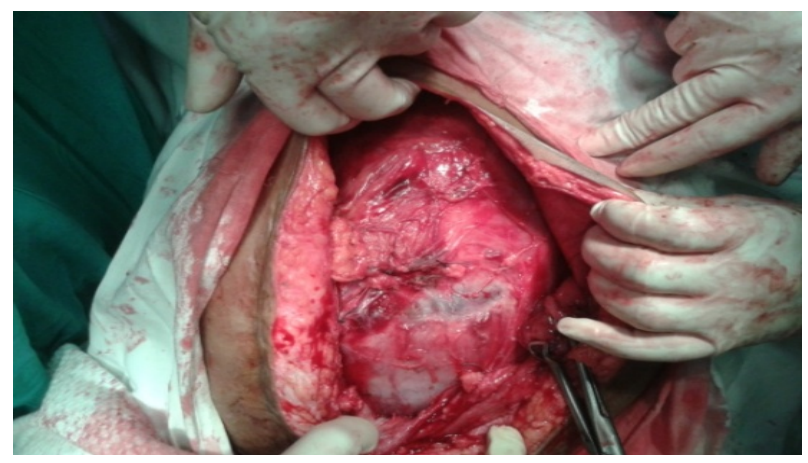

Figure 1. Photograph showing the badly adherent uterus released from anterior abdominal wall and placenta increta in lower uterine segment.

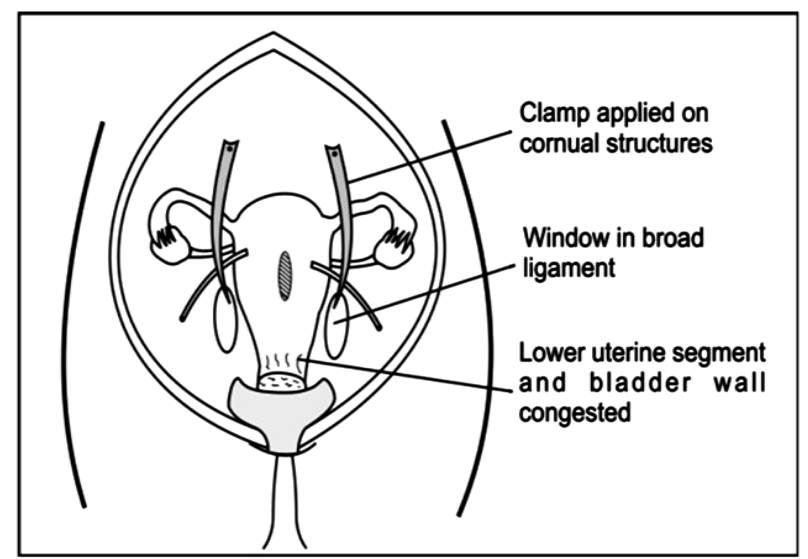

Figure 2. Sketch showing the creation of $2-3 \mathrm{~cm}$ window in the broad ligament lateral to uterus and application of clamps on the corneal structures. 


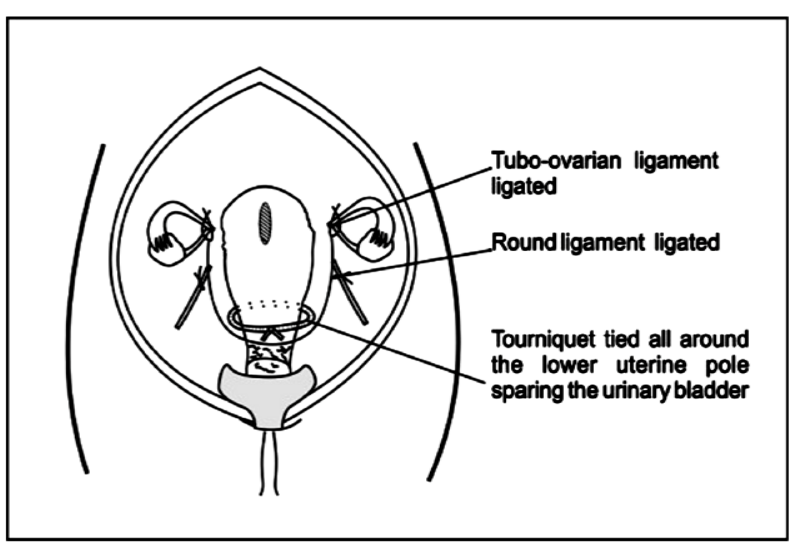

Figure 3. Sketch showing tourniquet passed through the window in the broad ligaments all around and tied tightly on to the lower pole of uterus.

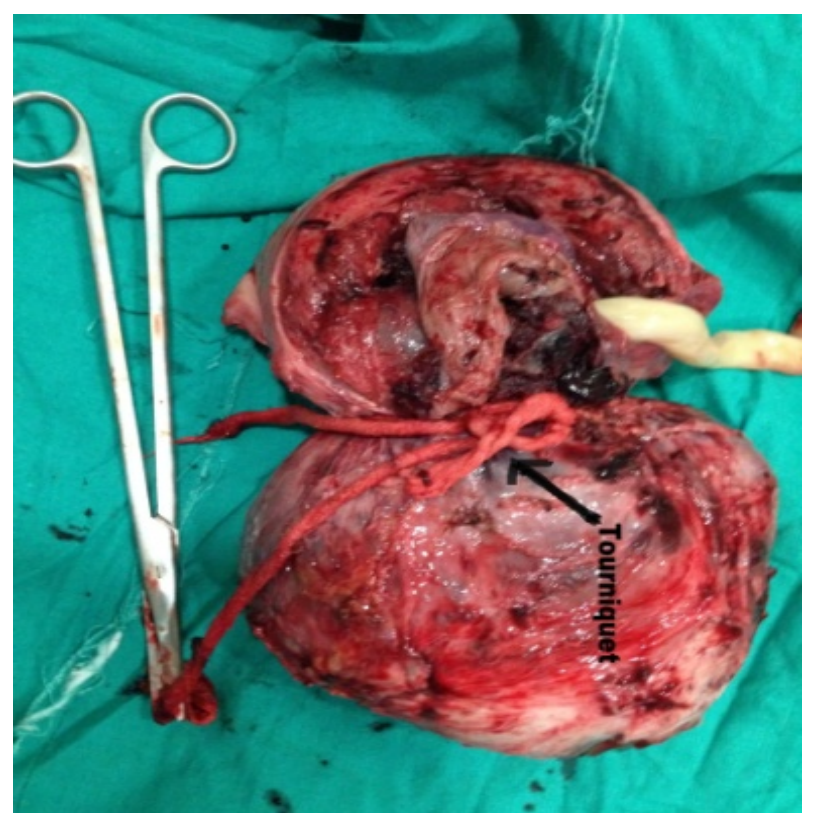

Figure 4. Specimen of uterus with placenta increta in-situ and tourniquet tied over the lower pole of uterus.

riorization of the uterus and application of clamps for abdominal hysterectomy using standard procedural steps and precautions. Post-operative $\mathrm{Hb}$ and hct was done and further blood was transfused as per need. Parameters such as pre-operative $\mathrm{Hb}$ and hct, post-operative $\mathrm{Hb}$ and hct, post-operative fall in Hb levels and hct, duration of surgery, need of vasopressors and ventilator support and total duration of hospital stay were recorded for the intervention group as well as the controls. Statistical analysis was done by computing the mean values, Standard deviation and data was compared using the Student's t-test. The results were considered significant when $\mathrm{p}$ value was $<0.05$ for the analysis.

\section{Results}

The nine cases undergoing cesarean hysterectomy using this novel approach were between 26 - 35 years of age, parity 2 to 5 , and belonged to middle socioeconomic group. They had at least one previous cesarean scar and mean pre-operative $\mathrm{Hb}$ of $10.43 \pm 0.69 \mathrm{gm} \%$ (Table 1 ). The control group was similar to cases with respect to demographic parameters $(\mathrm{p}>0.05)$. For the cases, cesarean hysterectomy was done under general anaesthesia 


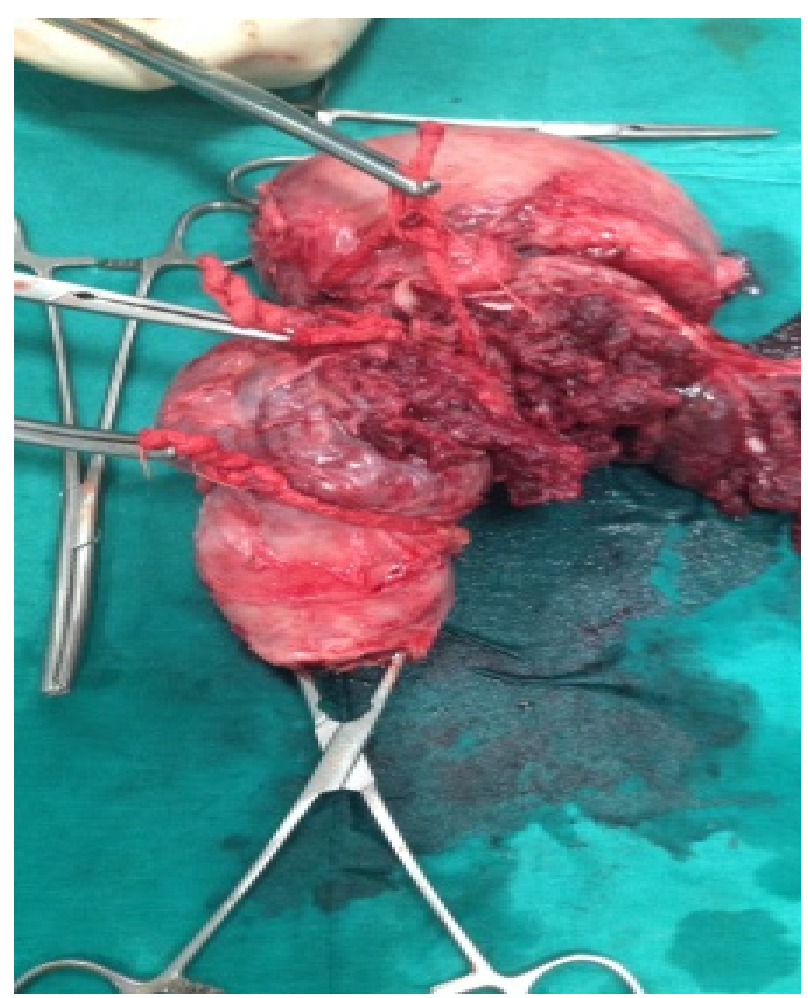

Figure 5. Specimen of uterus showing three tourniquets tied around it at the lower pole of uterus in case of placenta accreta with previous three LSCS.

Table 1. Demographic profile and comparative comprehensive analysis of subjects.

\begin{tabular}{|c|c|c|c|c|}
\hline S. No. & Parameter \pm SD & $\begin{array}{l}\text { Intervention group } \\
\mathrm{n}=\mathbf{9}\end{array}$ & $\begin{array}{c}\text { Controls } \\
\mathbf{n}=\mathbf{2 0}\end{array}$ & $\begin{array}{l}\text { Significance } \\
\quad \text { df }=27\end{array}$ \\
\hline 1. & Age (years) & $31.67 \pm 3.28$ & $30.9 \pm 4.29$ & $\mathrm{t}=0.477, \mathrm{p}=0.6368$ \\
\hline 2. & Parity & $3.22 \pm 1.09$ & $3.55 \pm 1.31$ & $\mathrm{t}=0.658, \mathrm{p}=0.515$ \\
\hline 3. & Gestational age at delivery (in weeks) & $35.17 \pm 0.83$ & $35.2 \pm 0.9$ & $\mathrm{t}=0.084, \mathrm{p}=0.932$ \\
\hline 4. & Preoperative $\mathrm{Hb}^{\mathrm{a}}$ (gm\%) & $10.43 \pm 0.69$ & $10.54 \pm 0.77$ & $\mathrm{t}=0.366, \mathrm{p}=0.716$ \\
\hline 5. & Preoperative $\mathrm{Hct}^{\mathrm{b}}\left(\mathrm{mm} \mathrm{1t}{ }^{\mathrm{st}} \mathrm{hr}\right)$ & $31.89 \pm 1.83$ & $32.3 \pm 1.92$ & $\mathrm{t}=0.539, \mathrm{p}=0.594$ \\
\hline 6. & Duration of surgery (minutes) & $85 \pm 11.72$ & $98.25 \pm 9.9$ & $\mathrm{t}=3.152, \mathrm{p}=0.0039^{*}$ \\
\hline 7. & Estimated blood loss (ml) & $1011.11 \pm 99.3$ & $1855 \pm 222.95$ & $\mathrm{t}=10.799, \mathrm{p} \leq 0.0001^{*}$ \\
\hline 8. & Postoperative $\mathrm{Hb}^{\mathrm{a}}$ (gm\%) & $8.57 \pm 0.51$ & $6.85 \pm 0.50$ & $\mathrm{t}=8.519, \mathrm{p} \leq 0.0001^{*}$ \\
\hline 9. & Postperative $\mathrm{Hct}^{\mathrm{b}}\left(\mathrm{mm} 1^{\mathrm{st}} \mathrm{hr}\right.$ ) & $26.89 \pm 1.53$ & $21.8 \pm 2.37$ & $\mathrm{t}=5.883, \mathrm{p} \leq 0.0001^{*}$ \\
\hline 10. & Blood transfusions (units) & $2.11 \pm 0.93$ & $4.45 \pm 1.47$ & $\mathrm{t}=4.373, \mathrm{p}=0.0002^{*}$ \\
\hline 11. & Duration of hospital stay (days) & $7.44 \pm 0.88$ & $10.3 \pm 1.83$ & $\mathrm{t}=4.430, \mathrm{p} \leq 0.0001^{*}$ \\
\hline 12. & Average fall in $\mathrm{Hb}^{\mathrm{a}}$ levels (gm\%) & $1.85 \pm 0.34$ & $3.67 \pm 0.92$ & $\mathrm{t}=5.713, \mathrm{p} \leq 0.0001^{*}$ \\
\hline 13. & Average fall in $\mathrm{Hct}^{\mathrm{b}}\left(\mathrm{mm}^{\mathrm{st}} \mathrm{hr}\right)$ & $4.44 \pm 1.33$ & $10.42 \pm 2.94$ & $\mathrm{t}=5.796, \mathrm{p} \leq 0.0001^{*}$ \\
\hline
\end{tabular}

$\mathrm{a}=$ Haemoglobin; $\mathrm{b}=$ Haematocrit; Note: ${ }^{*} \mathrm{p}<0.05$ = significant.

through midline incision. Operative time was 75 - 105 minutes. Amount of blood loss was between $85 \mathrm{ml}$ to $1300 \mathrm{ml}$. Average post-operative fall in $\mathrm{Hb}$ was $1.85 \pm 0.34 \mathrm{gm} / \mathrm{dl}$ and average fall in hct was $4.44 \% \pm 1.33 \%$. 
All cases required transfusion of two to five units of blood depending upon pre-operative Hb. One of the cases required vasopressors in the intraoperative period but was weaned off in the immediate post-operative period. None of the patients required ventilatory support in post-operative period (Table 2). Mean hospital stay was seven days with no major maternal complications. Neonatal outcome was favourable in all the cases. At six weeks postpartum both mother and baby did well in follow up.

Among the 20 controls undergoing cesarean hysterectomy for placenta accreta, the operative time was recorded to be between $85-130$ minutes. The operative blood loss was between $1400 \mathrm{ml}$ and $2500 \mathrm{ml}$. Average fall in post-operative $\mathrm{Hb}$ was $3.67 \pm 0.92 \mathrm{gm} / \mathrm{dl}$ and in hct was $10.42 \% \pm 2.94 \%$ (Table 1). Each patient required between 3 and 8 units of blood transfusions. Vasopressors were required preoperatively in two cases and intraoperatively in three cases. Ventilatory support was needed in two cases (Table 2). One patient developed febrile reaction after blood transfusion. The mean hospital stay was 10 days and all the twenty cases were discharged in a satisfactory condition. One neonate died as a result of milk aspiration.

On comparing the cases and controls (Table 1 ), the results show a striking difference with respect to mean operative time $(\mathrm{p}=0.0039)$, average intraoperative blood loss $(\mathrm{p}<0.0001)$, need for blood transfusion $(\mathrm{p}=$ $0.0002)$, postoperative fall in $\mathrm{Hb}(\mathrm{p} \leq 0.0001)$, fall in hct $(\mathrm{p} \leq 0.0001)$ and duration of hospital stay $(\mathrm{p} \leq 0.0001)$. All these parameters were significantly lesser for the cases as compared with the controls. On comparison amongst the cases with one, two and multiple tourniquet, the results show a longer duration of surgery for those with multiple tourniquet as compared with a single one, however, the blood loss was relatively less in cases where multiple tourniquet were applied (Table 3).

\section{Discussion}

The present study involves 29 cases of placenta accreta diagnosed on USG and Doppler who were managed with preterm planned cesarean sections followed by hysterectomy. In 9 of these, intraoperative tourniquet was applied in the lower segment and blood loss was compared with the non-intervention group. The subjects in both these groups were comparable with respect to age, parity and gestational age at the time of cesarean delivery (Table 1). Also, there were no differences between the groups with respect to Hb levels. All the subjects enrolled had prior uterine scarring from cesarean sections or myomectomies and most had a low lying placenta (Table 2). A significant difference was observed regarding the duration of surgery, intraoperative blood loss and postoperative fall in Hb levels between the two groups (Table 1). All these were significantly less in the intervention group. The use of tourniquet for reducing blood loss has shown beneficial results. Not only was there a significant shortening of the duration of surgery owing to better visibility of the surgical field with less blood loss, the amount of blood loss and need for transfusion of blood and components was also significantly less for the intervention group. The overall result was a shorter hospital stay with better recuperation amongst the intervention group and reduced morbidity (Table 2).

Maternal mortality and morbidity are significant in cases of morbidly adherent placenta despite optimal planning, transfusion management, and surgical care. As discussed earlier, the management of diagnosed cases of placenta accrete require a team of specialists inclusive of anaesthetists, obstetricians, urologists, intervention radiologists and neonatologists [9]. The recommended surgical approach for management of cases of placenta accreta is a planned preterm cesarean hysterectomy with the placenta left in situ [6]. A less radical approach or

Table 2. Risk factors and outcomes.

\begin{tabular}{cccc}
\hline S. No. & Parameter & Intervention group (n=9) & Controls (n= 20) \\
\hline 1. & Previous scarred uterus & 9 & 20 \\
2. & Placental previa & $7(77.8 \%)$ & 20 \\
3. & Placental accreta & 9 & $5(25 \%)$ \\
4. & Need of vasopressors & $1(11.11 \%)$ & $2(10 \%)$ \\
5. & Ventilator support & Nil & 1 (milk aspiration) \\
6. & Neonatal mortalities & Nil & Nil \\
7. & Maternal mortalities & Nil & \\
\hline
\end{tabular}


Table 3. Comparison of efficacy depending on number of tourniquets used.

\begin{tabular}{cccc}
\hline & One & Two & Three \\
\hline Average estimated blood loss (ml) & $1050 \pm 126.49$ & $975 \pm 106.06$ & 850 \\
Average operative time (minutes) & $80 \pm 4.47$ & $95 \pm 7.07$ & 105 \\
\hline
\end{tabular}

conservative approach may be needed in women wanting to preserve fertility.

Minimizing the intraoperative blood loss is critical for reducing maternal morbidity and mortality and various strategies have been explored and experimented for the same. Use of hypogastric artery catheterisation with balloon catheter occlusion has been associated with varied results. Although some investigators have reported reduced blood loss [10] [11], others have reported no benefits [12] and even significant complications [13]. Till date, there is insufficient evidence to recommend the use of balloon catheter occlusion embolization to reduce blood loss and improve surgical outcome, but individual situations may warrant their use.

We have utilized the novel technique of tourniquet application to prevent excessive blood loss per-operatively in cesarean hysterectomies for placenta accreta which helped in reducing blood transfusion requirements, serious maternal morbidity and mortality. The results show a significant and definite benefit of tourniquet application in cesarean hysterectomies for placenta accreta not only by reducing the intra-operative blood loss but also by reducing the duration of surgery and thus maternal morbidity. This study is an impetus to further research on the use of tourniquet in peripartum hysterectomy. Having an established role in myomectomy [14], we can conclude that this technique of tourniquet application might be helpful in desperate obstetric emergencies. This may be yet another way to reduce blood loss and a step forward towards decreasing maternal mortality.

\section{Conclusions}

Management of placenta accreta is a challenge for every obstetrician. A proper planning, competent surgical technique, availability of blood, team work of the staff, ICU ventilatory support are required at the tertiary care centre to save maternal life and also reduce serious morbidity related to massive blood loss and transfusion. Our technique can be one such step to minimize the blood loss intra-operatively and thus in reducing the complications of massive blood transfusion, decrease in maternal morbidity and mortality.

We acknowledge the antenatal women who consented to participate in the study. There is no conflict of interest among the authors.

\section{References}

[1] Wu, S., Kocherginsky, M. and Hibbard, J.U. (2005) Abnormal Placentation: Twenty-Year Analysis. American Journal of Obstetrics \& Gynecology, 192, 1458-1461.

[2] Silver, R.M., Landon, M.B., Rouse, D.J., Leveno, K.J., Spong, C.Y., Thom, E.A., et al. (2006) Maternal Morbidity Associated with Multiple Repeat Cesarean Deliveries. National Institute of Child Health and Human Development Maternal-Fetal Medicine Units Network. Obstetrics \& Gynecology, 107, 1226-1232. http://dx.doi.org/10.1097/01.AOG.0000219750.79480.84

[3] Committee on Obstetric Practice (2002) ACOG Committee Opinion No. 266. Placenta Accreta. International Journal of Gynecology \& Obstetrics, 77, 77-78.

[4] Shellhaas, C.S., Gilbert, S., Landon, M.B., Varner, M.W., Leveno, K.J., Hauth, J.C., et al. (2009) The Frequency and Complication Rates of Hysterectomy Accompanying Cesarean Delivery. Eunice Kennedy Shriver National Institutes of Health and Human Development Maternal-Fetal Medicine Units Network. Obstetrics \& Gynecology, 114, $224-229$. http://dx.doi.org/10.1097/AOG.0b013e3181ad9442

[5] Eller, A., Porter, T., Soisson, P. and Silver, R. (2009) Optimal Management Strategies for Placenta Accreta. BJOG: An International Journal of Obstetrics \& Gynaecology, 116, 648-654. http://dx.doi.org/10.1111/j.1471-0528.2008.02037.x

[6] (2012) Placenta Accreta. Committee Opinion No. 529. American College of Obstetricians and Gynecologists. Obstetrics \& Gynecology, 120, 207-211. http://dx.doi.org/10.1097/AOG.0b013e318262e340

[7] Hudon, L., Belfort, M.A. and Broome, D.R. (1998) Diagnosis and Management of Placenta Percreta: A Review. Obstetrical \& Gynecological Survey, 53, 509-517. http://dx.doi.org/10.1097/00006254-199808000-00024

[8] O’Brien, J.M., Barton, J.R. and Donaldson, E.S. (1996) The Management of Placenta Percreta: Conservative and Operative Strategies. American Journal of Obstetrics \& Gynecology, 175, 1632-1638. 
http://dx.doi.org/10.1016/S0002-9378(96)70117-5

[9] Eller, A.G., Bennett, M.A., Sharshiner, M., Masheter, C., Soisson, A.P., Dodson, M., et al. (2011) Maternal Morbidity in Cases of Placenta Accrete Managed by a Multidisciplinary Care Team Compared with Standard Obstetric Care. Obstetrics \& Gynecology, 117, 331-337. http://dx.doi.org/10.1097/AOG.0b013e3182051db2

[10] Tan, C.H., Tay, K.H., Sheah, K., Kwek, K., Wong, K., Tan, H.K., et al. (2007) Perioperative Endovascular Internal Iliac Artery Occlusion Balloon Placement in Management of Placenta Accreta. American Journal of Roentgenology, 189, 1158-1163. http://dx.doi.org/10.2214/AJR.07.2417

[11] Ojala, K., Perala, J., Kariniemi, J., Ranta, P., Raudaskoski, T. and Tekay, A. (2005) Arterial Embolization and Prophylactic Catheterization for the Treatment for Severe Obstetric Hemorrhage. Acta Obstetricia et Gynecologica Scandinavica, 84, 1075-1080.

[12] Shrivastava, V., Nageotte, M., Major, C., Haydon, M. and Wing, D. (2007) Case-Control Comparison of Cesarean Hysterectomy with and without Prophylactic Placement of Intravascular Balloon Catheters for Placenta Accreta. American Journal of Obstetrics \& Gynecology, 197, 402.e1-402.e5.

[13] Bishop, S., Butler, K., Monaghan, S., Chan, K., Murphy, G. and Edozien, L. (2011) Multiple Complications Following the Use of Prophylactic Internal Iliac Artery Balloon Catheterisation in a Patient with Placenta Percreta. International Journal of Obstetric Anesthesia, 20, 70-73. http://dx.doi.org/10.1016/j.ijoa.2010.09.012

[14] Taylor, A., Sharma, M., Tsirkas, P., Di Spiezio Sardo, A., Setchell, M. and Magos, A. (2005) Reducing Blood Loss at Open Myomectomy Using Triple Tourniquets: A Randomised Controlled Trial. BJOG: An International Journal of Obstetrics \& Gynaecology, 112, 340-345. http://dx.doi.org/10.1111/j.1471-0528.2004.00430.x 
Scientific Research Publishing (SCIRP) is one of the largest Open Access journal publishers. It is currently publishing more than 200 open access, online, peer-reviewed journals covering a wide range of academic disciplines. SCIRP serves the worldwide academic communities and contributes to the progress and application of science with its publication.

Other selected journals from SCIRP are listed as below. Submit your manuscript to us via either submit@scirp.org or Online Submission Portal.
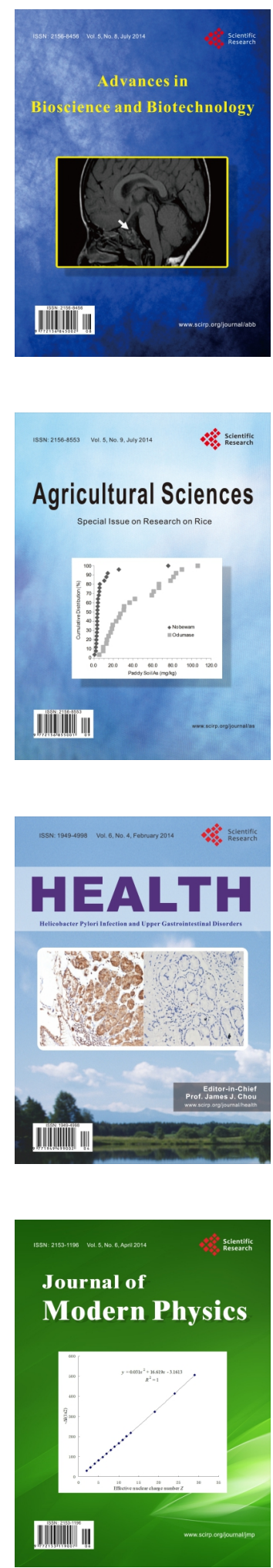
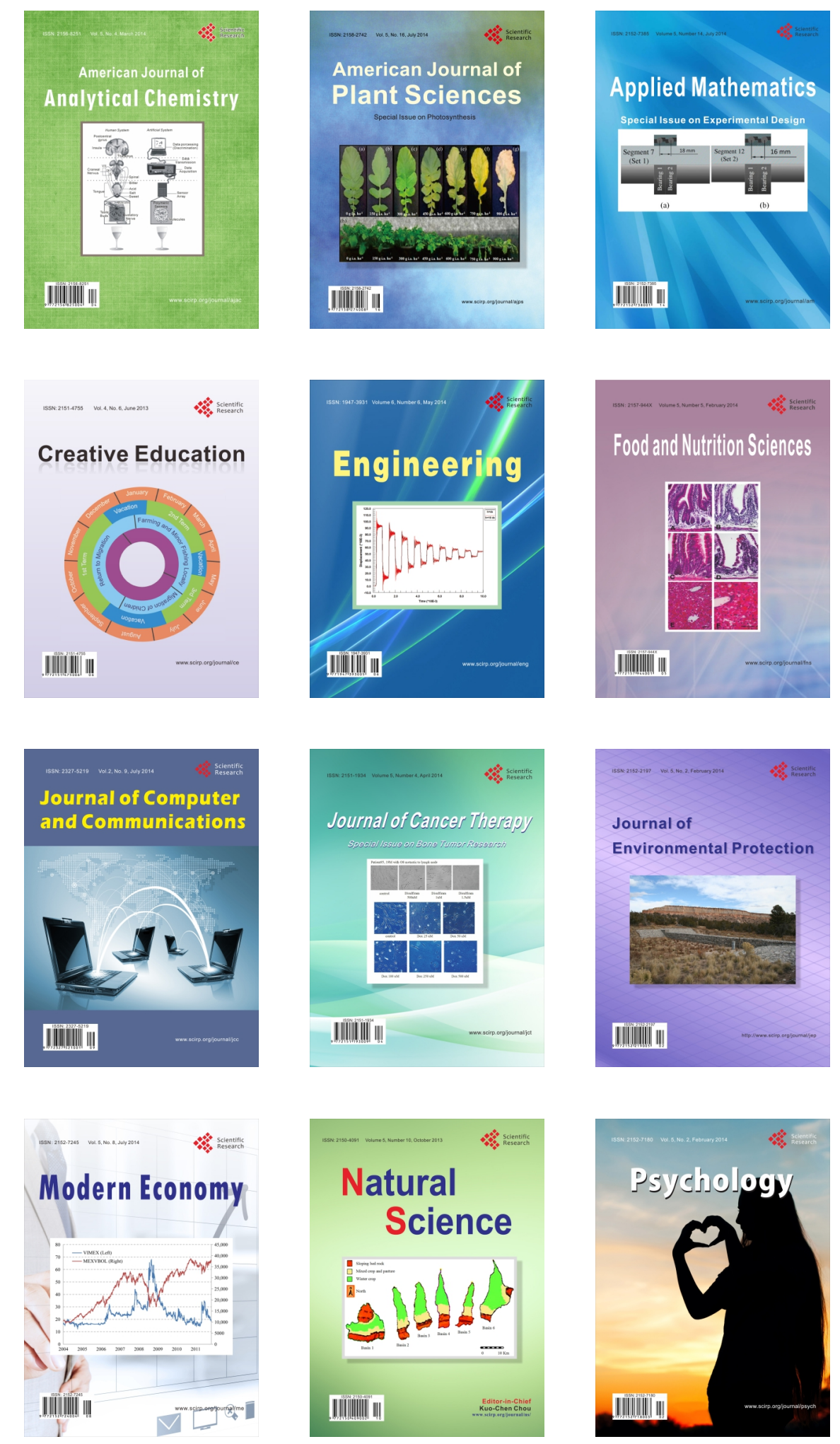